\title{
Synthesis and Sulfation of Branched Dextrans
}

\author{
Kenichi Hatanaka, ${ }^{\dagger}$ Takakazu HiRobe, Takashi Yoshida, \\ Midori YamanaKa, and Toshiyuki UYRU* \\ Institute of Industrial Science, University of Tokyo, \\ Roppongi, Minato-ku, Tokyo 106, Japan
}

(Received November 29, 1989)

\begin{abstract}
Di- $O$-benzyl- $(1 \rightarrow 6)-\alpha$-D-glucopyranan, which was synthesized by ringopening polymerization of 1,6-anhydro-2,4-di-O-benzyl-3-O-tert-butyldimethylsilyl- $\beta$-D-glucopyranose and subsequent desilylation, was $\beta$-glucosylated or $\alpha$-mannosylated by the orthoester method. Deprotection of glycosylated polysaccharides with sodium in liquid ammonia was performed to give branched dextrans with free hydroxyl groups. Sulfation of the branched dextrans was carried out with piperidine $N$-sulfonic acid in dimethylsulfoxide to give new heparinoids. The Polymers were characterized by NMR spectroscopy, gel permeation chromatography, and optical rotation.

KEY WORDS Ring-Opening Polymerization / Anhydrosugar / Branched Polysaccharide / Dextran / Sulfated Polysaccharide / Orthoester Method /
\end{abstract}

Many natural polysaccharides and oligosaccharides participate in a variety of biochemical reactions in vivo. Recently, the relation between the chemical structure of carbohydrate and its biological functions has been reported in detail. Some investigators noted that both the structures of main chain and branching sugar unit are important for the polysaccharide to exhibit biochemical functions. An elicitor-active oligosaccharide which induces phytoalexins (antibiotics) in plant cells was purified from the mycelial walls of Phytophthora megasperma f. sp. glycinea ${ }^{1}$ and its primary structure was revealed to be $\beta$ - $(1 \rightarrow 6)$-linked glucopentaose with $\beta$-D-glucopyranosyl branch at $\mathrm{C}-3$ position of 2 nd and 4th glucose residues. ${ }^{2}$ Furthermore, the elicitor-active oligosaccharide was chemically synthesized $^{3}$ for its elicitor activity to be compared with that of the mycelial-wall-derived heptasaccharide. ${ }^{4}$ Panaxans were extracted from the roots of Panax ginseng to elucidate the structures of substances responsible for its lowering blood sugar levels. ${ }^{5}$ A partial structure of hypoglycaemic glycans, i.e., panaxans $A$ and $B$, was presumed to be $\alpha-(1 \rightarrow 6)$ linked D-glucopyranans having an $\alpha$-D-glucopyranosyl branch at the C-3 position. ${ }^{6}$ A chemically synthesized panaxan which was obtained by ring-opening copolymerization of 1,6-anhydro-glucose and 1,6-anhydro-nigerose derivatives showed a significant hypoglycaemic activity in mice. ${ }^{7}$

The structure of a pentasaccharide residue was found to be the active site of blood anticoagulant in heparin. ${ }^{8}$ Some investigators have reported the total synthesis of the heparin pentasaccharide fragment which showed specific binding to antithrombin III and also induced high anti-Xa activity. ${ }^{9,10} \mathrm{We}$ reported the synthesis of sulfated polysaccharides which showed high anticoagulant activities ${ }^{11}$ and potent inhibitory effects on infection and replication of human immunodeficiency

\footnotetext{
* To whom correspondence should be addressed.

$\dagger$ Present Address: Department of Biomolecular Engineering, Faculty of Engineering, Tokyo Institute of Technology, Nagatsuta, Midori-ku, Yokohama 227, Japan.
} 
virus. ${ }^{12}$ Villanueva predicted the secondary structure of antithorombin III and the location of the heparin-binding site where the three lysine residues interact with one 6-O-sulfate and two 2 - $N$-sulfates in heparin. ${ }^{13,14}$

The cationic ring-opening polymerization of 1,6-anhydro-glucose derivatives with Lewis acid as an initiator gave stereoregular $(1 \rightarrow 6)$ $\alpha$-D-glucopyranan derivatives. ${ }^{15,16}$ Most natural dextrans have an $\alpha-(1 \rightarrow 6)$-linked backbone with $\alpha$-D-glucopyranosyl or $\alpha$-D-isomaltosyl units at C-3 position. ${ }^{17}$ Ito and Schuerch Synthesized $(1 \rightarrow 6)-\alpha$-D-glucopyranan having $\alpha$-D-glucopyranosyl branch at C-3 by ringopening polymerization of 1,6-anhydro-2,4di- $O$-benzyl-3- $O$-crotyl- $\beta$-D-glucopyranose, which can be regioselectively deprotected at C-3 after polymerization, followed by glucosylation and debenzylation. ${ }^{18}$ Previously, we attempted to synthesize $(1 \rightarrow 6)-\alpha$-D-glucopyranan bearing 3-O-( $\alpha$-D-mannopyranosyl) branches by the ring-opening polymerization of 3-O-tert-butyldimethylsilylated 1,6-anhydro-glucose derivative and by subsequent branching. ${ }^{19}$

In this investigation, we report the synthesis and sulfation of $(1 \rightarrow 6)-\alpha$-D-glucopyranan with 3- $O$-( $\beta$-D-glucopyranosyl) or 3-O-( $\alpha$-D-mannopyranosyl) branches.

\section{EXPERIMENTAL}

\section{General Methods}

NMR spectra were recorded on a JEOL GX-270 spectrometer in chloroform- $d$ and deuterium oxide using tetramethylsilane (TMS) and sodium 4,4-dimethyl-4-silapentanesulfonate (DSS) as the internal standards, respectively. Gel permeation chromatography was run on $3 \%$ solutions of polymers in tetrahydrofuran by a Toyo Soda high-speed chromatograph (model HLC 802UR). The number-average molecular weights calculated by GPC were based on polystyrene calibration curve. The number-average molecular weights of water-soluble polysaccharides were de- termined by aqueous-phase gel permeation chromatography (columns, Toyo Soda TSKgel; eluent, 66.7 mM phosphate buffer, $\mathrm{pH}$ 6.86) using standard dextrans as reference. Sulfur content analysis was performed by Ajinomoto Co., Ltd., analytical laboratory. Optical rotations were measured in chloroform or water at $25^{\circ} \mathrm{C}$ with Perkin-Elmer Model 241 polarimeter using a 1-dm cell.

\section{Polymerization and desilylation}

Polymerization of 1,6-anhydro-2,4-di- $O$ benzyl-3- $O$-tert-butyldimethylsilyl- $\beta$-D-glucopyranose and regioselective deprotection (desilylation) of the obtained polymer were carried out as described previously. ${ }^{19}$

Glycosylation with 3,4,6-tri-O-acetyl- $\alpha$-D-glucopyranose-1,2-(t-butyl orthoacetate)

$3,4,6$-Tri- $O$-acetyl- $\alpha$-D-glucopyranose-1,2( $t$-butyl orthoacetate) was prepared from pentaacetyl $\beta$-D-glucose according to the literature. $^{20}$

Glucosylation was carried out in chlorobenzene with 2,6-lutidinium perchlorate as the catalyst. $^{20} \quad 2,4-\mathrm{Di}-O$-benzyl- $(1 \rightarrow 6)-\alpha$-D-glucopyranan $(300 \mathrm{mg}, 0.88 \mathrm{mmol})$ and 3,4,6-tri- $O$ acetyl- $\alpha$-D-glucopyranose-1,2-( $t$-butyl orthoacetate) $(1.05 \mathrm{~g}, 2.60 \mathrm{mmol})$ were dissolved in chlorobenzene $(25 \mathrm{ml})$, and the solution was refluxed for $1 \mathrm{~h}$ using Dean-Stark trap. After distillation of $10 \mathrm{ml}$ of solvent, 2,6-lutidinium perchlorate $(1.8 \mathrm{mg})$ was added and the mixture was refluxed for $40 \mathrm{~min}$. Purification of the polymer was performed three times by dissolution-reprecipitation using a chloroformmethanol system. Polymer was freeze-dried from benzene. All operations were repeated two times. (Yield, $357 \mathrm{mg}$ )

Glycosylation with 3,4,6-tri-O-acetyl- $\beta$-D-man-
nopyranose-1,2-(methyl orthoacetate)
$\alpha$-Mannosylation was performed with mannose orthoester as described previously. ${ }^{19}$ The mole ratio of 2,4 -di- $O$-benzyl- $(1 \rightarrow 6)-\alpha$-D-glucopyranan and 3,4,6-tri- $O$-acetyl- $\beta$-D-manno- 
pyranose-1,2-(methyl orthoacetate) was $1: 3$.

\section{Deprotection of branched polysaccharides}

A branched polysaccharide (glucosylated polymer, $140 \mathrm{mg}$ ) was dissolved in $8 \mathrm{ml}$ of 1,2-dimethoxyethane and the solution was added to $30 \mathrm{ml}$ of liquid ammonia containing $140 \mathrm{mg}$ of sodium at $-78^{\circ} \mathrm{C}$. After $1.5 \mathrm{~h}$, ammonium chloride was added until the blue color completely disappeared and then a small amount of methanol and $10 \mathrm{ml}$ of distilled water were added successively. After evaporation of ammonia, the deprotected polysaccharide solution was washed several times with methylene chloride and the solution was dialyzed for 3 days with running water. The branched polysaccharide was freeze-dried from water. Yield, $44.5 \mathrm{mg}(66.5 \%)$.

\section{Sulfation of Branched Polysaccharides}

Sulfation of deprotected polyasccharide with piperidine $N$-sulfonic acid ${ }^{23}$ was carried out according to the method of Nagasawa et al. ${ }^{24}$

Glucose-branched polysaccharide $(47 \mathrm{mg})$ was dissolved in $7 \mathrm{ml}$ of dry dimethylsulfoxide. Piperidine $N$-sulfonic acid (448 mg) was added to the solution. The reaction mixture was heated for $1 \mathrm{~h}$ at $85^{\circ} \mathrm{C}$ under stirring. After cooling in a water bath, $7 \mathrm{ml}$ of saturated sodium bicarbonate solution were added. The mixture was dialyzed successively with running saturated sodium bicarbonate solution overnight and running distilled water for 3 days and concentrated below $35^{\circ} \mathrm{C}$. The sulfated polysaccharide was freeze-dried from water. Yield, $88 \mathrm{mg}$ (91.5\%).

\section{RESULTS AND DISCUSSION}

Synthesis of 2,4-di-O-benzyl-( $(\rightarrow \sigma)-\alpha-\mathrm{D}-$ glucopyranan (3)

Ring-opening polymerization of 1,6-anhydro-2,4-di-O-benzyl-3-O-tert-butyldimethylsilyl- $\beta$-D-glucopyranose (1) catalyzed by phosphorus pentafluoride $(3 \mathrm{~mol} \%)$ in dichloromethane at $-60^{\circ} \mathrm{C}$ gave stereoregular 2,4-di-
$O$-benzyl-3-O-tert-butyldimethylsilyl-( $1 \rightarrow 6)$ $\alpha$-D-glucopyrananan (2) having a numberaverage molecular weight of $6.6 \times 10^{4}$ in high yield. The ${ }^{1} \mathrm{H}$ NMR spectrum of the polymer was assigned by 2 -dimensional ${ }^{1} \mathrm{H}-{ }^{1} \mathrm{H}$ COSY spectrum (Figure 1). Desilylation of the polymer was performed with tetrabutylammonium fluoride in tetrahydrofuran ${ }^{19}$ to give a regioselectively deprotected 2,4 -di- $O$-benzyl$(1 \rightarrow 6)-\alpha$-D-glucopyranan 3 . It is noteworthy that the tert-butyldimethylsilyl group, easily removed with fluoride anions, was stable to hexafluorophosphate anion during polymerization.

\section{Glycosylation of 2,4-di-O-benzyl-( $(1 \rightarrow \sigma)-\alpha-\mathrm{D}-$ glucopyranan}

$\beta$-Glucosylation was carried out with 2,6lutidinium perchlorate as catalyst in nitrobenzene according to the method of Kochetkov $^{20}$ as summarized in Table I. The mole ratio of the glucose residues ( $=$ free hydroxyl groups) to the orthoester was $1: 3$. The obtained polymer (4) was easily dissolved in organic solvents such as benzene, acetone, and chloroform. Mole fraction of the glucosylated residues in the main chain was 0.25 , as determined from the ${ }^{1} \mathrm{H}$ NMR spectrum by measuring the intensity of methyl protons in the acetyl group. Low degree of glucose branching may possibly have been due to the low stability of the tert-butyl orthoester. ${ }^{21} \mathrm{Re}$ glucosylation of the glucosylated polymer in the same way gave a more branched polymer. The mole fraction of the glucosylated residues was 0.36. As shown in Figure 2, the ${ }^{13} \mathrm{C}$ NMR spectrum of the reglucosylated polymer showed absorptions due to acetyl groups at $20-21$ and $169-171 \mathrm{ppm}$ originating from the glucosyl branch. It was found that the $\mathrm{C}-1$ carbon resonance consisted of two peaks; a larger one at higher field $(97 \mathrm{ppm})$ was assignable to $\alpha$-anomeric carbon in the main chain $(\alpha-(1 \rightarrow 6)$ linked) and the other at lower field (101 ppm) was attributed to the $\beta$-anomeric carbon of the branch $(\beta-(1 \rightarrow 3)$-linked). The mole fraction of 


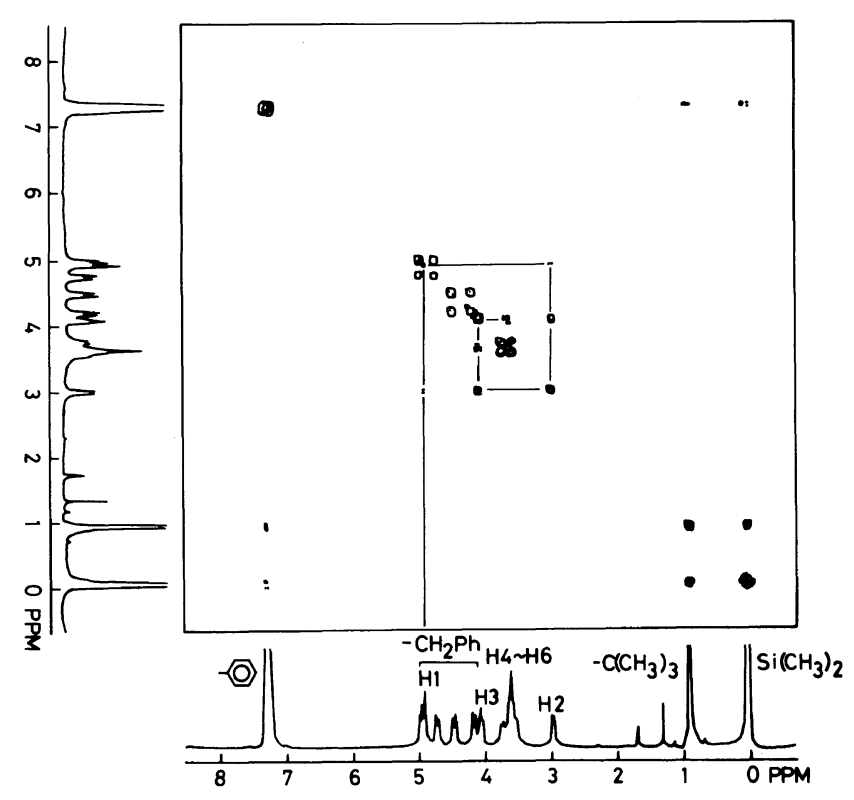

Figure 1. Contour plot of $\mathrm{H}-\mathrm{H}$ COSY spectrum of 2,4-di-O-benzyl-3-O-tert-butyldimethysilyl-(1 $\rightarrow 6)$ $\alpha$-D-glucopyranan (2).
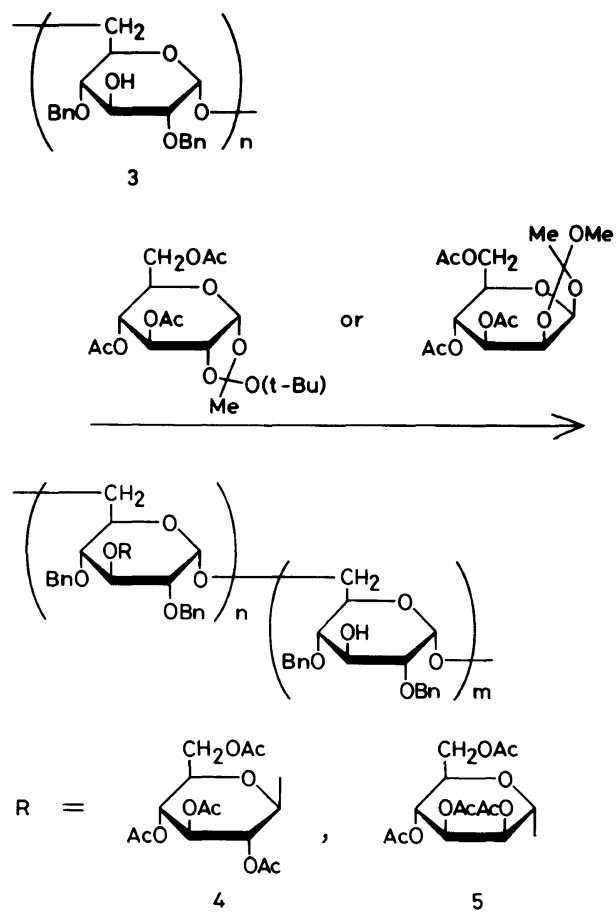

Table I. Glycosylation of 2,4-di- $O$-benzyl$(1 \rightarrow 6)-\alpha-D-$ glucan $^{a}$

\begin{tabular}{|c|c|c|c|c|c|}
\hline No. & Orthoester $^{\mathbf{b}}$ & $\frac{\text { Yield }}{\%}$ & $\frac{[\alpha]_{D}^{25 c}}{\operatorname{deg}}$ & $\frac{\bar{M}_{n}^{\mathrm{d}}}{\times 10^{4}}$ & $\begin{array}{l}\text { Mole frac- } \\
\text { tion of } \\
\text { glycosylated } \\
\text { unit in } \\
\text { main chain }\end{array}$ \\
\hline 1 & Glucose & 100 & +95.4 & 6.8 & 0.25 \\
\hline $2^{f}$ & Glucose & 89 & +94.6 & 7.7 & 0.36 \\
\hline 3 & Mannose & 100 & +128.0 & 10.1 & 0.67 \\
\hline
\end{tabular}

a Starting polymer, $\bar{M}_{n}=6.3 \times 10^{4}$; concentration of polymer in chlorobenzene, $20-29 \mathrm{mg} \mathrm{ml}^{-1}$; catalyst, lutidinium perchlorate, $1 \mathrm{~mol} \%$ to free hydroxyl groups in the polymer; temp., reflux; time, $40-45 \mathrm{~min}$.

b Mole ratio of the glucose residues to the orthoester was $1: 3$.

c Measured in chloroform ( $c$ 1).

d Determined by GPC using THF.

e Calculated with PMR.

f Reglucosylation of No. 1.

the glucosylated residues in the main chain was calculated from the ${ }^{13} \mathrm{C}$ NMR spectrum by the C-1 absorptions to give almost the same value (0.44) as that from ${ }^{1} \mathrm{H}$ NMR (0.36), indicating 


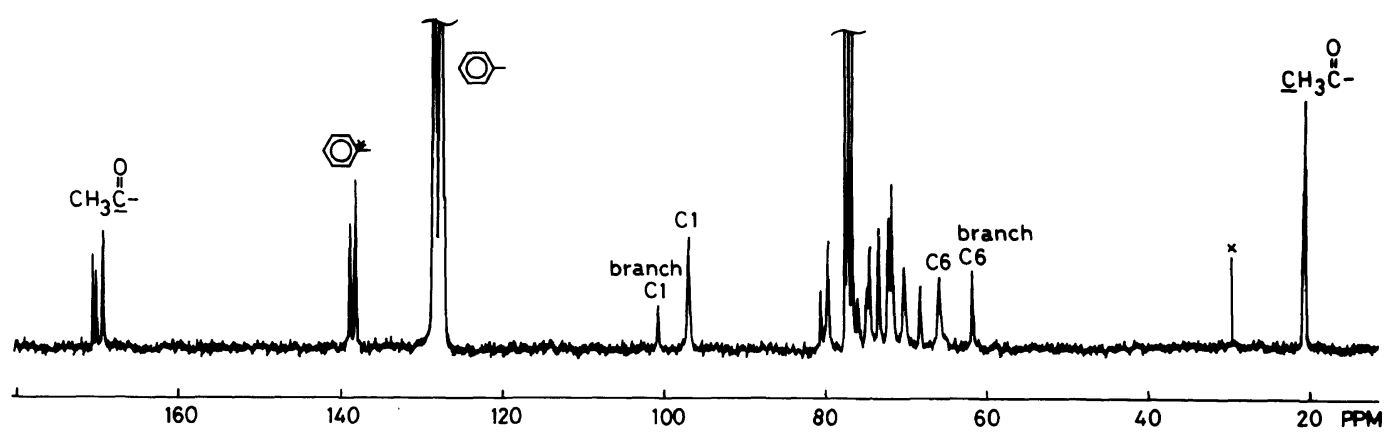

Figure 2. ${ }^{13} \mathrm{C}$ NMR spectrum of glucosylated polysaccharide (4).
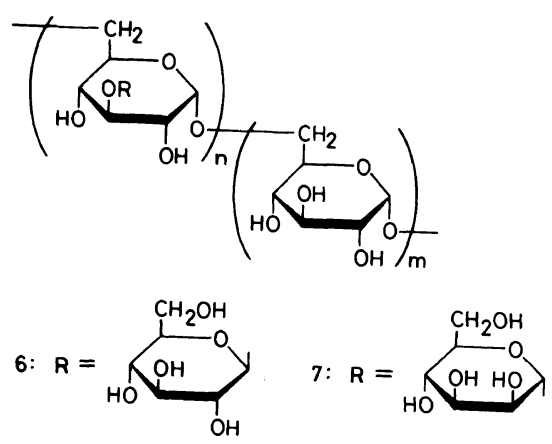

the glucosylation stereoselectively to have occurred $(100 \% \beta)$.

$\alpha$-Mannosylation was carried out with 3,4,6-tri- $O$-acetyl- $\beta$-D-mannopyranose-1,2(methyl orthoacetate) as described previously. ${ }^{19}$ The mole fraction of mannosylated residues in the main chain was 0.67 as calculated from the ${ }^{1} \mathrm{H}$ NMR spectrum.

During the desilylation and glycosylation, main chain scission did not take place. 2 with $\overline{D P}_{n}$ of 145 was reacted to give a $\beta$-glucosylated polymer with $\overline{D P}_{n}$ (main chain) of 167 and an $\alpha$-mannosylated polymer with $\overline{D P}_{n}$ (main chain) of 179.

Removal of Protective Groups into Branched Polysaccharides Having Free Hydroxyl Groups

Deprotection of branched polysaccharide was earied out with sodium in liquid ammonia at $-78^{\circ} \mathrm{C}$ (Table II). The ${ }^{1} \mathrm{H}$ and ${ }^{13} \mathrm{C}$ NMR
Table II. Simultaneous deprotection of branched polysaccharides $^{a}$

\begin{tabular}{|c|c|c|c|c|c|c|}
\hline \multirow{2}{*}{ No. } & \multicolumn{2}{|c|}{$\begin{array}{l}\text { Starting } \\
\text { polymer }\end{array}$} & \multirow{2}{*}{$\frac{\mathrm{Na}}{\mathrm{mg}}$} & \multirow{2}{*}{$\frac{\text { Yield }}{\%}$} & \multirow{2}{*}{$\frac{[\alpha]_{\mathrm{D}}^{25 \mathrm{~b}}}{\operatorname{deg}}$} & \multirow{2}{*}{$\begin{array}{l}\text { Mole frac- } \\
\text { tion of } \\
\text { glycosylated } \\
\text { unit in } \\
\text { main chain }\end{array}$} \\
\hline & kind & $\mathrm{mg}$ & & & & \\
\hline 1 & 4 & 140 & 140 & 68.8 & +137.8 & 0.44 \\
\hline 2 & 5 & 310 & 510 & 61.6 & +110.2 & 0.70 \\
\hline
\end{tabular}

a Temp., $-78^{\circ} \mathrm{C}$; time, $90 \mathrm{~min}$.

b Measured in water $(c 0.5)$.

c Calculated with CMR.

spectra of deprotected glycosylated polysaccharide (6) in $\mathrm{D}_{2} \mathrm{O}$ showed the complete removal of protective groups (Figure 3). Benzyl groups in the main chain and acetyl groups in the branching unit were simultaneously removed under this condition. Figure $3 \mathrm{~A}$ shows that glucosylated polysaccharide has two kinds of C-1 carbons. The peak at the lower field $(105.5 \mathrm{ppm})$ was assignable to the anomeric carbon of the branch $(\beta-(1 \rightarrow 3)$-linked $)$, since the $\mathrm{C}-1$ carbon of lentinan $((1 \rightarrow 3)-\beta$-D-glucan with branching) appeared at $106 \mathrm{ppm}$. The mole fraction of glucosylated residues in the main chain, as calculated from the C-1 absorption, was 0.44 . The mannosylated fraction of 7 was also determined to be 0.70 (Figure 3B).

\section{Sulfation of Branched Polysaccharides}

Sulfation of branched polysaccharides 6 and 

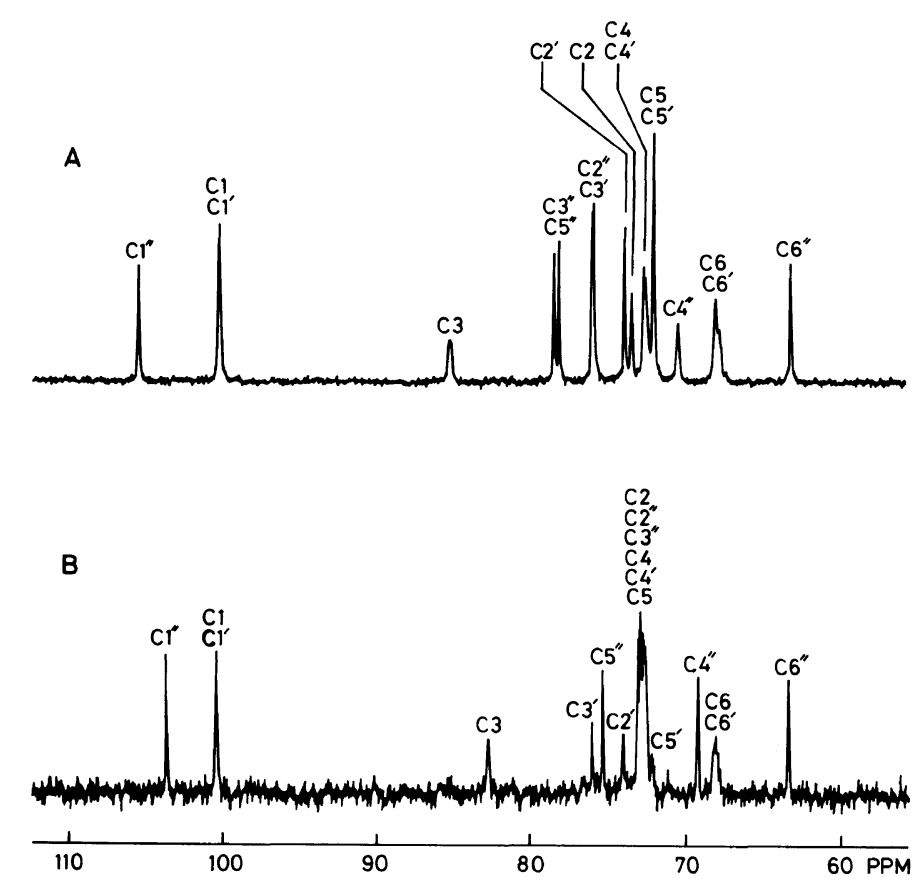

Figure 3. ${ }^{13} \mathrm{C}$ NMR spectra of $(1 \rightarrow 6)-\alpha$-D-glucopyrananans with (A) 3- $O$ - $(\beta$-D-glucopyranosyl) and (B) 3-O-( $\alpha$-D-mannopyranosyl) branches (6 and 7). Peaks are assignable to carbons in three kinds of sugar residues as follows. $C_{n}(n=1 \sim 6)$, main chain with branching; $C_{n}{ }^{\prime}$, main chain without branching; $C_{n}{ }^{\prime \prime}$, branching sugar unit.

Table III. Sulfation of branched dextrans ${ }^{\mathbf{a}}$

\begin{tabular}{|c|c|c|c|c|c|c|c|}
\hline \multirow{2}{*}{ No. } & \multicolumn{2}{|c|}{ Starting polymer } & \multirow{2}{*}{$\frac{\text { DMSO }}{\mathrm{ml}}$} & \multirow{2}{*}{$\begin{array}{c}\text { Piperidine } \\
N \text {-sulfonic acid } \\
\mathrm{mg}\end{array}$} & \multirow{2}{*}{$\frac{\text { Yield }}{\%}$} & \multirow{2}{*}{$\begin{array}{c}\begin{array}{c}\text { Sulfur } \\
\text { content }\end{array} \\
\%\end{array}$} & \multirow{2}{*}{$\frac{\bar{M}_{n}^{\mathrm{b}}}{\times 10^{4}}$} \\
\hline & kind & $\mathrm{mg}$ & & & & & \\
\hline 1 & 6 & 47 & 7 & 450 & 88 & 14.4 & 4.69 \\
\hline 2 & 7 & 81 & 14 & 820 & 130 & 15.5 & 5.34 \\
\hline
\end{tabular}

a Temp., $85^{\circ} \mathrm{C}$; time, $1 \mathrm{~h}$.

b Dtermined by GPC using phosphate buffer.

7 was carried out with piperidine $N$-sulfonic acid in a homogeneous dimethyl sulfoxide solution. The results are summarized in Table III.

Sulfated polysaccharides were colored with a toluidine blue solution, indicating the presence of sulfate groups. A mixture of sulfated mannosyl polysaccharide (9) and toluidine blue solution became purplish red, in contrast to royal purple for sulfated glucosyl polysaccharide (8). The color reaction of sulfated ribofuranan ${ }^{11}$ which has cis substituents showed purplish red. ${ }^{22}$ In the case of sulfated xylofuranan ${ }^{11}$ which has trans substituents, the color was royal purple. ${ }^{22}$ The reddish color was probably due to the cis substituent.

The number of sulfate group per sugar unit 
was calculated by elemental analysis. 8 had 1.7 sulfur atoms per sugar unit and 9 had 2.0. Both 8 and 9 contained a small amount of water. ${ }^{13} \mathrm{C}$ NMR spectrum of 9 indicated that the primary hydroxyl groups of all branching sugar units were sulfated, since the absorption of C-6 carbon shifted downfield $(5-6 \mathrm{ppm})$ after the sulfation.

The number average degree of polymerization of 8 as determined by GPC was 98 with 43 branching units, indicating that a few chain scissions had occurred. $\overline{D P}_{n}$ of 9 was 86 with 61 branchings. More sulfation might cause more main chain scissions.

\section{REFERENCES AND NOTES}

1. J. K. Sharp, B. Valent, and P. Albersheim, J. Biol. Chem., 259, 11312 (1984).

2. J. K. Sharp, M. McNeil, and P. Albersheim, J. Biol. Chem., 259, 11321 (1984).

3. (a) P. Ossowski, §. Pilotti, P. J. Garegg, and B. Lindberg, J. Biol. Chem., 259, 11337 (1984). (b) P. Ossowski, A. Pilotti, P. J. Garegg, and B. Lindberg, Angew. Chem. Int. Ed. Engl., 22, 793 (1983).

4. J. K. Sharp, P. Albersheim, P. Ossowski, Å. Pilotti, P. Garegg, and B. Lindberg, J. Biol. Chem., 259, 11341 (1984).

5. C. Konno, K. Sugiyama, M. Kano, M. Takahashi, and H. Hikono, Planta Medica, 434 (1984).

6. (a) M. Tomoda, K. Shimada, C. Konno, K. Sugiyama, and H. Hikono, Planta Medica, 436 (1984). (b) M. Tomoda, K. Shimada, C. Konno, and H. Hikino, Phytochemistry, 24, 2431 (1985).

7. H. Kuzuhara, Y. Ichikawa, N. Sakairi, T. Uryu, and T. Yoshida, Int. Carbohydr. Symposium,
Stockholm, Aug., 1988.

8. I. Bjork and U. Lindahl, Mol. Cell. Biochem., 48, 161 (1982).

9. M. Petitou, P. Duchaussoy, I. Lederman, J. Choay, P. Sinay, J.-C. Jaquinet, and G. Torri, Carbohydr. Res., 147, 221 (1986).

10. Y. Ichikawa, R. Monden, and H. Kuzuhara, Carbohydr. Res., 172, 37 (1988).

11. K. Hatanaka, T. Yoshida, S. Miyahara, T. Sato, F Ono, T. Uryu, and H. Kuzuhara, J. Med. Chem., 30 , 810 (1987).

12. K. Hatanaka, T. Yoshida, T. Uryu, O. Yoshida, H. Nakashima, N. Yamamoto, T. Mimura, and Y. Kaneko, Jpn. J. Cancer Res., 80, 95 (1989).

13. G. B. Villanueva, J. Biol. Chem., 259, 2531 (1984).

14. U. Lindahl, G. Backstorm, L. Thunberg, and I. G. Leder, Proc. Natl. Acad.Sci. U.S.A., 77, 6551 (1980).

15. E. R. Ruckel and C. Schuerch, J. Org. Chem., 31, 2233 (1966).

16. (a) T. Uryu, H. Tachikawa, K. Ohaku, K. Terui, and K. Matsuzaki, Makromol. Chem., 178, 1929 (1977). (b) T. Uryu, K. Hatanaka, K. Matsuzaki, and H. Kuzuhara, Macromolecules, 16, 853 (1983).

17. (a) B. Lindberg and S. Svensson, Acta Chem. Scand., 22, 1907 (1971). (b) O. Larm, B. Lindberg, and S. Svensson, Carbohydr. Res., 20, 39 (1971).

18. H. Ito and C. Schuerch, J. Am. Chem. Soc., 101, 5797 (1979).

19. T. Uryu, M. Yamanaka, M. Henmi, K. Hatanaka, and K. Matsuzaki, Carbohydr. Res., 157, 157 (1986).

20. N. K. Kochetkov and A. F. Bochkov, Methods Carbohydr. Chem., 6, 480 (1972).

21. B. Pfannemüller, G. C. Richter, and F. Husemann, Carbohydr. Res., 56, 139 (1977).

22. K. Hatanaka, unpublished result.

23. K. Nagasawa and H. Yoshidome, Chem. Pharm. Bull., 17, 1316 (1969).

24. K. Nagawawa, H. Harada, S. Hayashi, and T. Misawa, Carbohydr. Res., 21, 420 (1972). 